\title{
Designing Algorithms for Evaluating the Effectiveness of Remote Banking Systems
}

\author{
Aleksandr V. Belov \\ National Research University Higher School of Economics \\ Philip D. Zagumennov \\ National Research University Higher School of Economics
}

\begin{abstract}
The objective of this research is to develop a software algorithm for evaluating the effectiveness of using the Financial Message Transfer System for Remote Banking Systems. The study considers interactions between the legal entity and the bank that are provided by two types of systems: "Direct Banking» and "Internet Banking». During the work the main features of remote banking systems and the efficiency criteria are identified and analyzed. In accordance with the proposed mathematical model, a software algorithm was constructed to obtain quantitative estimates of Remote Banking Systems effectiveness. The developed algorithm belongs to the heuristic class.
\end{abstract}

Keywords: Remote Banking Systems, Transaction, Efficiency Criteria

\section{INTRODUCTION}

In the age of information technologies it is important for contractors to provide comfortable and effective data transmission. In particular, financial messages transmission should be uninterrupted and secured. These indicators are provided by several well-known data systems such as Remote Banking System (RBS) and Financial Message Transfer System (FMTS).

Financial Message Transfer System is a unified system created on the basis of the Bank of Russia information and telecommunications (IT) system, which was created as an alternative way of interaction between contractors that ensures the direct, secured, confidential and uninterrupted transmission. For Russian counterparties, the advantages of using FMTS are familiarity and previous interaction with the IT services of the Bank of Russia.

Remote banking is the way to provide banking services to the Client, based on the fact that the Client does not need to visit the bank by himself. The service is performed remotely via telecommunications systems such as RBS.

The combination of Remote Banking and Financial Message Transfer systems forms a unified interaction module that has the best performance indicators.

Evaluating the effectiveness of these systems is diversified. On the one hand, the client must understand the significance of quantitative indicators from which it will be advantageous to use RBS in combination with FMTS. On the other hand, it is important for the bank to recoup the connection costs incurred through the establishment of monthly fees, tariffs, etc. 
The mathematical model and software algorithm considered in this paper give quantitative estimates of the effectiveness of the use of RBS in combination with FMTS. The following parameters are considered in the proposed mathematical model:

- The cost of connection to FMTS and the cost of software required for proper operation;

- The cost of connection to RBS and the cost of tools that ensure uninterrupted transmission;

- The cost of modification of integrated systems to provide correct and uninterrupted system operation;

- The quantity of financial messages transmitted by Client;

- The costs and tariffs for the transaction made using each of the systems;

- The monthly cost of system maintenance.

Further, in this paper, we will consider an existing types of interactions, their pros and cons, the advantages of FMTS and the model developed to reflect the efficiency of using RBS.

\section{ANALYSIS OF EXISTING REMOTE BANKING TYPES OF INTERACTIONS}

This section overviews the strength and the weaknesses of the existing types of interactions between the legal entity and the bank.

\section{Direct Banking}

This type of interaction is often called a "thick client". In order to ensure uninterrupted operation, the Client needs a personal computer (PC), with the unique banking software (software) for remote maintenance. This type of relationship, or interaction, is secure, security provides reliable systems by means of data encryption and integrity control.

The advantages of «Direct Banking» are as follows:

- The Client has no need for a permanent connection to the banking component of the RBS system;

- The rich and simple in understanding feature set, which includes the possibility of incidents analysis.

The disadvantages of «Direct Banking» are as follows:

- A large quantity of components are necessary to ensure uninterrupted interaction of the Customer with the bank through the RB system: the PC with installed software, a communication channel (Internet) etc.

- Every bank has its own RB software to support the Client's work. Thus, the Customer's expenses for connection to the RB systems are directly proportional to the number of interacted banks.

\section{FIGURE 1 \\ VISUALIZATION OF "DIRECT BANKING" INTERACTION}

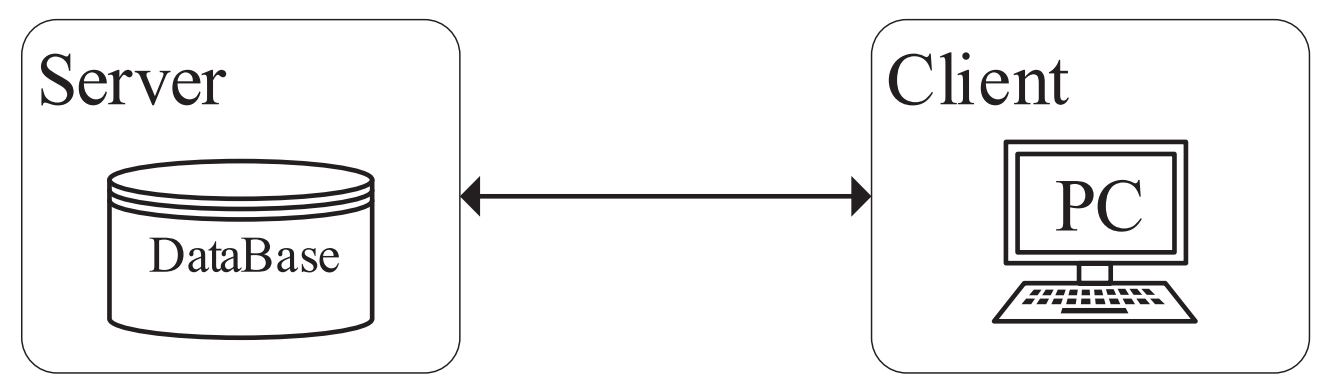




\section{Internet Banking}

This type of interaction is often referred to as "thin client". The difference between this type of interaction and the others is that the Client interacts with the bank via the Internet browser, and the RB system itself is directly located on the bank's web server.

The advantages of «Internet Banking» are as follows:

- The possibility of modification with the least cost of the Client's systems (For example: Accounting systems) for further integration with the remote maintenance system;

- The low cost of providing secure and uninterrupted interaction.

However, the main disadvantage of this type of interaction is "vulnerability" from unauthorized access, since the Client performs its work with the global network using a browser.

FIGURE 2

\section{VISUALIZATION OF "INTERNET BANKING" INTERACTION}

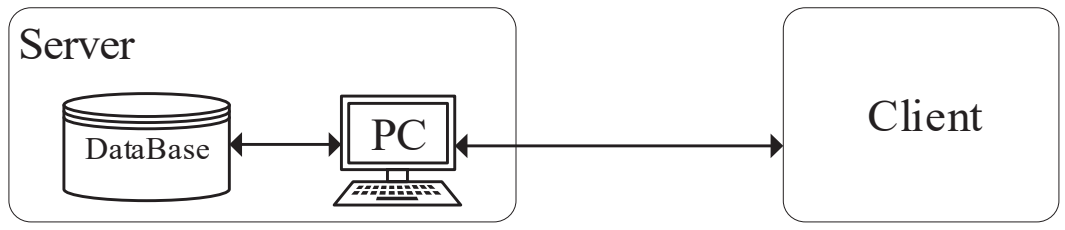

\section{FINANCIAL MESSAGE TRANSFER SYSTEM AND ITS USAGE FOR REMOTE BANKING SYSTEMS}

Each of the RBS interactions between the bank and the Client is a separate and an independent figure.

FIGURE 3

VISUALIZATION OF "INTERNET BANKING" INTERACTION
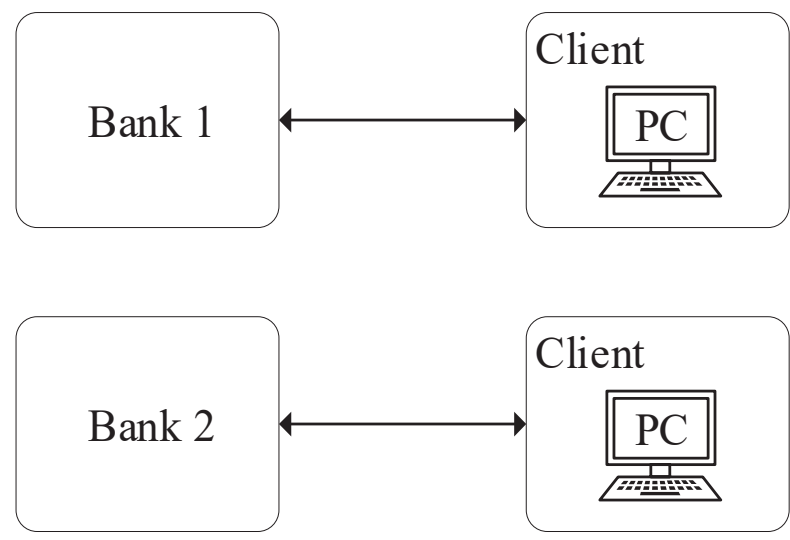

By using RBS in combination with FMTS, all interactions are conducted through a single "module". The work is provided with the help of the so-called "Automated Workstation of the Bank of Russia Client" (AWS BRC). AWS BRC is an application software that is used to organize the transfer of financial messages. The AWS BRC software consists of two main parts: an operator and a controller, each of which requires a separate PC. 
FIGURE 4

VISUALIZATION OF "INTERNET BANKING" INTERACTION

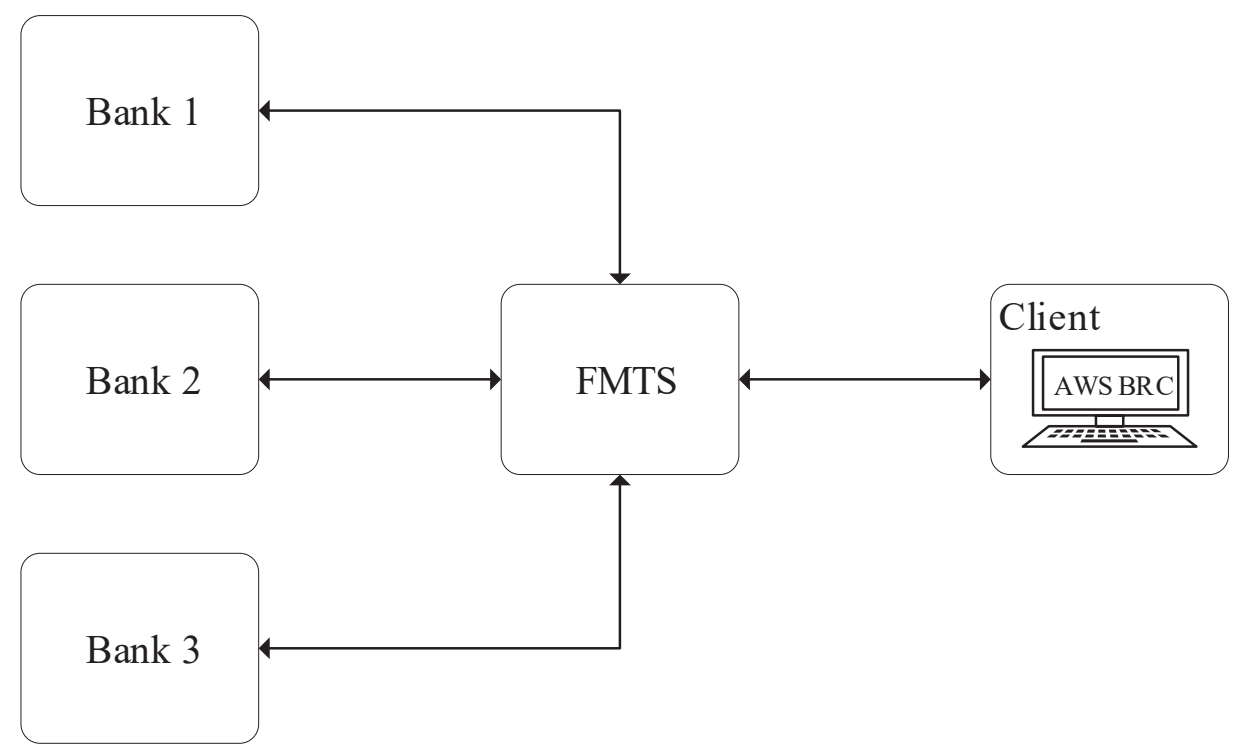

Comparing this figure with the figure of interactions using RBS, it can be stated that the "module" of FMTS unifies the interactions between the Banks and the Client.

\section{MATHEMATICAL MODEL FOR EVALUATING THE EFFECTIVENESS OF FINANCIAL MESSAGE TRANSFER SYSTEM}

To construct a heuristic model that shows the Customer's benefit in selecting RBS in combination with FMTS in place of traditional RBS, the following hypotheses are formulated:

- The Client transfers financial messages using the "package", i.e. determines all the payment orders accumulated during the operational day in one order for repayment;

- Assume that the bank processes the order for debt repayment as one payment, i.e. bank charges a fee in the amount of one transaction for all the payment orders contained in the "package";

- Based on the data disclosed by the corporations, assume that the company (legal entity), which is classified as large (income over 2 billion Russian rubles), on average transfers 2000-2500 financial messages per day through one bank;

Based on the cost of modernization of accounting systems, consider that for companies, which are classified as large, the cost of modernization ranges from 10 to 30 million Russian rubles.

\section{The Input Parameters of Mathematical Model}

Based on the generated hypotheses, the input parameters of the model were identified:

TABLE 1

\section{THE INPUT PARAMETERS OF MATHEMATICAL MODEL}

The quantity of transferred financial messages per day in one bank, Q(Quantity)
The estimated quantity of days for using the system, $\mathrm{D}$ (Days)
The costs for integrated system modernization, $\mathrm{O}($ Once $)$ 


\section{The Total Equation and Dependencies}

Define the equation that shows the benefit of using RBS in combination with FMTS in place of traditional RBS:

Total Profit $=$ Constant + Profit - Once - Fee

where:

- C (Constant) - The indicator of the quantitative benefit of connecting systems, which is calculated as the difference between the one-time costs of connecting systems:

- The one-time costs for connection to «Direct Banking» system is 261956.00 thousand Russian rubles;

- The one-time costs for connection to «Internet Banking» system is 114869.00 thousand Russian rubles;

- The one-time costs for connection to FTMS is 395276.00 thousand Russian rubles.

- P (Profit) - The indicator of the quantitative benefit from the transfer of "package" transactions, which is calculated by the following equation:

$P . \sum_{i=1}^{N}\left(T_{1}^{i} * \quad+T_{2}^{i}\right)-\sum_{i=1}^{N} * T_{2}^{i}$

where:

o $\quad i$ - the index of the corresponding servicing bank. Varies from 1 to $\mathrm{N}$;

o $\quad \mathrm{T}_{1}^{\mathrm{i}}$ - the appropriate tariff for the transfer of one message in FMTS;

o $\quad \mathrm{T}_{2}^{\mathrm{i}}$ - the appropriate tariff for the transfer of one message in RBS.

- O (Once) - One-time costs for the modernization of integrated systems. Under general assumptions, it means a variable parameter. For companies, which are classified as large the cost of modernization ranges from 10 to 30 million Russian rubles;

- F (Fee) - The quantitative value of the monthly fee, calculated depending on the number of expected days of using the system and the number of servicing banks:

$\mathrm{F}=\frac{\mathrm{M}^{*} \mathrm{~N} * \mathrm{D}}{30}$

where:

o M (Month) - Monthly fee for the provision of RB systems, set by each of the banks separately;

o $\mathrm{N}$ (Number) - Number of banks servicing the Client;

o D (Days) - Estimated time for using the remote maintenance system.

\section{Functional Testing}

Based on the proposed mathematical model, software algorithm was built including all the proposed dependencies.

To verify the quality of work and to visualize the result of the constructed algorithm, the input data were taken from the disclosed company's LUKOIL information. The company LUKOIL is classified as large and is one of the leaders in the market of oil products. LUKOIL, like many representatives of its field, successfully switched to the FMTS for traditional RBS.

Data for functional testing:

- Q (Quantity): During the day, LUKOIL makes about Q (Quantity) = 20,000 transactions (transferred financial messages) such as: payment of wages, payment of taxes and duties, provision of financial statements (usually one message) etc. 
- P (Profit): Considering the parameter, the data of five largest banks were disclosed (VTB, Alfa-Bank, Gazprombank, Rosselkhoz Bank and Sberbank). As a unification, five tariffs for RBS were randomly modeled in the range of 6 to 15 Russian rubles for each transaction and their average value was calculated. The benefit is: $\mathrm{P}=15175.00 \mathrm{P}$

- (Once): For LUKOIL company, which is classified as large the cost of modernization is 30 million Russian rubles.

- $\mathrm{M}$ (Month): Each of the banks, in addition to payment for the transaction, takes a monthly fee. The model used the average value of the monthly fee among the five above-mentioned banks. So the fee for using RBS systems is:

o 6175.00 thousand Russian rubles for «Direct Banking»;

o 950.00 thousand Russian rubles for «Internet Banking».

Based on the proposed data, the indicators of final benefit were obtained:

TABLE 2

FUNCTIONAL TESTING. INPUT DATA

\begin{tabular}{|l|l|l||}
\hline \multicolumn{3}{|c|}{ Input data (per day) } \\
\hline $\begin{array}{l}\text { The quantity of } \\
\text { transferred financial } \\
\text { messages per day in one } \\
\text { bank, }\end{array}$ & $\begin{array}{l}\text { The estimated quantity } \\
\text { of days for using the } \\
\text { system, } \\
\text { D(Days) }\end{array}$ & $\begin{array}{l}\text { The costs for } \\
\text { integrated system } \\
\text { modernization, } \\
\text { O(Once) }\end{array}$ \\
\hline 2000 & \multicolumn{3}{|r|}{$30000000,00 \mathrm{P}$} \\
\hline
\end{tabular}

TABLE 3

FUNCTIONAL TESTING. DIRECT BANKING USAGE PROFIT

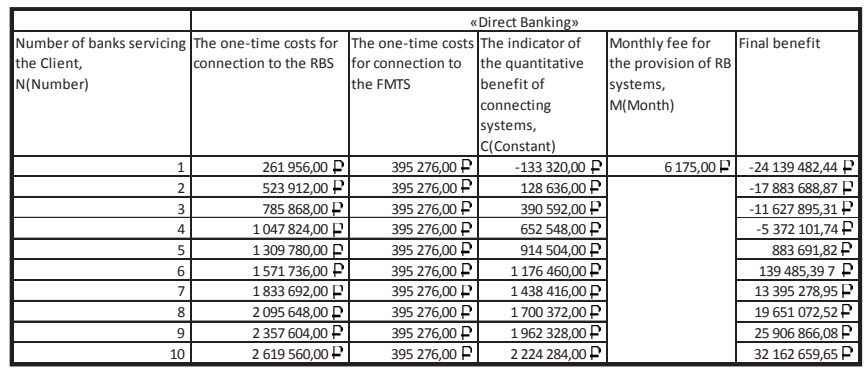

TABLE 4

FUNCTIONAL TESTING. INTERNET BANKING USAGE PROFIT

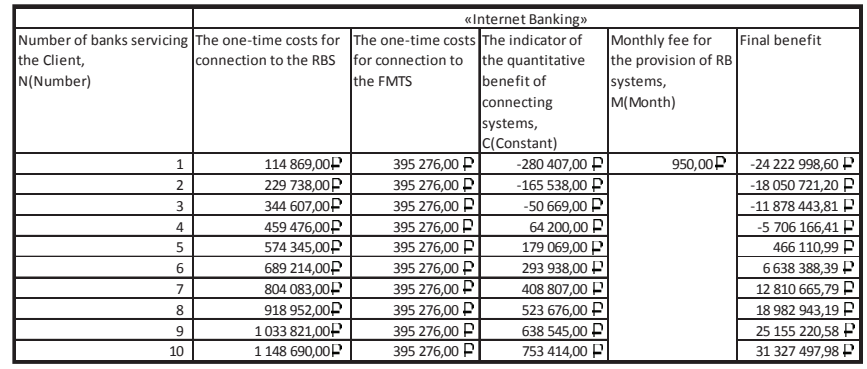

Thus, the tables (TABLE 3 and 4) show how much money a client could receive in a given period of time, interacting with a certain number of banks in one of two types of relationship "Direct Banking" or "Internet Banking" with FMTS rather than the traditional RB interaction channel. 


\section{CONCLUSION}

Based on the constructed mathematical model and the developed algorithm, a quantitative indicator of "benefit" was obtained depending on the input parameters.

The following diagram visualizes the result:

FIGURE 5

REPRESENTATION OF RESULT

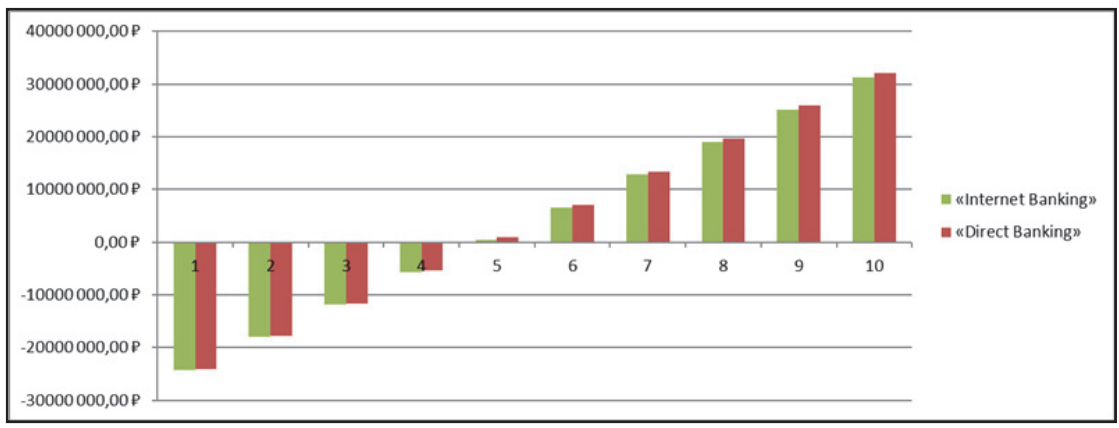

From this diagram, it can be concluded that the company LUKOIL, at its given level of input parameters, interacting with more than five different banks should save from 0.5 to 32.2 million Russian rubles.

\section{REFERENCES}

Abdalkrim, G.M., \& Khrai, L.T. (2013). The Impact of Strategic planning on online banking an empirical study in (Saudi environment). American Journal of Business and Management, 2(1).

Aljawarneh, S.A (2016). Online Banking Security Measures and Data Protection. United States of America. Information Science Reference Publ., p.312.

Avtorov, K. (2010). Distancionnoebankovskoeobsluzhivanie [Remote banking system]. Moscow, KNORUS Publ., p.453.

Khrais, L.T. (2013). The Effectiveness Of E- Banking Environment in Customer Life Service an Emperical Study. Polish Journal of Management Studies, 8.

Sistemaperedachifinansovykhsoobshcheniy (Financial Message Transfer System). (n.d.). Retrieved from http://www.cbr.ru/psystem/mes

Strader, T.J., \& Carter, R.B. (2001). Electronic Banking: The Ultimate Guide to Business and Technology of Online Banking. United States of America, Vieweg Publ., p.208.

Turbanov, A. (2010). Bankovskoedelo.Operacii,tekhnologii,upravlenie [Banking. Operations, technology, management]. Moscow, Al'pina Publ., p.679.

Willis, H.P., \& Edwards, G.W. (1922). Banking and Business. United States of America. Harper \& Brothers Publishers, p.563.

Zharkovskaja, E. P. (2016). Bankovskoedelo [Banking]. Moscow, OMEGA-L Publ., p.528. 